\title{
Efficacy in standard clinical practice of colonoscopic polypectomy in reducing colorectal cancer incidence
}

F Citarda, G Tomaselli, R Capocaccia, S Barcherini, M Crespi, The Italian Multicentre Study Group

\begin{abstract}
Background-Colorectal cancer is one of the leading causes of death from cancer in Western countries. Removal of adenomas is based on the assumption that it could lead to a reduction in the incidence of colorectal cancer, as demonstrated by the National Polyp Study in the USA. A critical issue is whether the benefit observed in clinical trials can also be observed in standard clinical practice. To address the issue, a multicentre Italian collaborative study was organised.
\end{abstract}

Methods-The study cohort comprised 1693 subjects of both sexes, aged 40-69 years, enrolled between 1980 and 1987 following a total colon examination (TCE) (that is, total colonoscopy or colonoscopy and double contrast barium enema), with removal of at least one adenoma larger than $5 \mathrm{~mm}$ in diameter. Exclusion criteria were genetic syndromes, previous adenomas or colorectal cancer, previous colonic resection, inflammatory bowel disease, or sessile adenomas more than $3 \mathrm{~cm}$ in diameter. Follow up ended in December 1996 by TCE or telephone interview, and review of the medical records, clinical files, or death certificates. Incidence ratios for colorectal cancer were compared with expected age and sex specific incidences in the Italian general population.

Results-Follow up data were obtained for $\mathbf{9 7 . 3 \%}$ of cases for a total of 14211 person/ years. Mean follow up was 10.5 years. Six colorectal cancer cases (four in males, two in females) at various stages were ascertained (one at 29 months, two at five years, one at seven years, one at eight years, and one at $\mathbf{1 0}$ years from the index examination). The number of cancers expected in the reference population was 17.7 for an incidence ratio of 0.34 (confidence interval $0.23-0.63 ; \mathrm{p}<0.01$ ).

Conclusions-Colonoscopic polypectomy substantially reduced the incidence of colorectal cancer in the cohort compared with that expected in the general population. These results are of particular relevance considering that those with adenomas are at increased risk of colorectal cancer and that this retrospective study was performed on data obtained in standard clinical practice. This observation strengthens the concept of effective population screening in view of the fact that adenomatous polyps are the most frequent neoplastic outcome of screening and their removal is associated with a decrease in the incidence of colorectal cancer.

(Gut 2001;48:812-815)

Keywords: colorectal cancer; colonoscopy; clinical practice; screening

Several prospective and retrospective studies have shown that removal of adenomatous polyps is associated with a reduction in the incidence of colorectal cancer. The strongest evidence was presented by a prospective colonoscopy study, the National US Polyp Study (NPS), which showed a lower than expected incidence of colorectal cancer at follow up, with a protective effect over an average of 5.9 years of follow up. ${ }^{1}$ Two retrospective case control studies $^{23}$ of sigmoidoscopy reported a reduction in mortality in the rectosigmoid area as a result of screening which we conclude is a result of polypectomy. Another endoscopic retrospective study $^{4}$ showed a reduction in incidence after endoscopic screening.

A major question is whether the magnitude of the benefit observed in a prospective colonoscopy trial would be observed in clinical practice. To address this question, a collaborative group of endoscopists in Italy retrospectively examined the long term outcome of colonoscopic polypectomy in their clinical practices.

\section{Methods}

PATIENTS

All patients aged 40-69 years and who had a total colon examination (TCE), that is, total colonoscopy or partial colonoscopy and double contrast barium enema (DCBE) between 1980 and 1987, and who had removal of at least one adenoma of $0.5 \mathrm{~cm}$ in size or larger were incorporated into the database. All identified polyps were removed. Subjects with inflammatory bowel disease, genetic syndromes such as familial adenomatous polyposis or hereditary non-polyposis colorectal cancer, previous colorectal cancer or adenomas, sessile adenomas more than $3 \mathrm{~cm}$ in diameter, or previous colonic resection were excluded from the study. The upper age limit of 69 years was chosen to ensure an adequate follow up interval

Abbreviations used in this paper: TCE, total colon examination; DCBE, double contrast barium enema; NPS, National US Polyp Study; FOBT, faecal occult blood test; MIAMOD, mortality incidence analysis model. 
considering the retrospective design of the study. Patients were scheduled for clinical, radiological, and endoscopic follow up examinations based on the individual protocols of the participating centres. Data were collected from seven participating centres considered in Italy as reference centres for gastrointestinal diseases and neoplasms, capable of providing significant numbers of cases and using common histopathological criteria based on the WHO classification. ${ }^{5}$ The centres provided the central unit with a form for each eligible case, with endoscopic, histopathological, and clinical data. For subjects who had colorectal surgery, operative and pathology reports were also obtained. Close contact between the central unit and collaborating centres ensured collection and completion of clinicopathological and follow up data.

Follow up ended in December 1996 with results of a TCE performed at follow up in the last two years or by telephone interview with the patient. If the patient could not be reached, data on vital status were obtained from the population registry of the municipality. For those who had died before the follow up period ended, relatives and family doctors were contacted and clinicopathological data were obtained from hospital records or death certificates.

Colorectal cancers diagnosed within two years from the index examination were excluded, and considered as missed lesions. Persons/years at risk are derived from two years after initial colonoscopy until final status.

\section{REFERENCE POPULATION AND STATISTICAL}

ANALYSIS

Reference incidence rates are usually taken from a comparable population covered by cancer registries. However, cancer registries during the study period included only a proportion of the national population (8-12\%) and were unevenly distributed within Italy, being mostly concentrated in the north of the country where both incidence and mortality rates of colorectal cancer are higher than the national average. ${ }^{6}$ Using cancer registry populations as a reference would lead to overestimation of the expected probabilities of developing cancer by about $10 \%$. Following an alternative approach, we derived reference incidence rates of colorectal cancer by mortality incidence analysis model (MIAMOD) statistical modelling. The MIAMOD approach $^{78}$ estimates incidence rates of a chronic disease using a non-linear regression model of mortality. Incidence is modelled as a parametric function of age, period, and cohort. Expected mortality rates are calculated from incidence and known survival data. The parameters of the incidence function are then estimated by maximum likelihood as those for which expected mortality best fits the observed rates.

The model has previously been tested and applied in Italy to estimate the incidence and prevalence of colorectal $^{9}$ and other frequent cancers. ${ }^{10-12}$ For the present application, official mortality data of colorectal cancer were obtained by year, age, and sex from the
National Statistical Institute. Relative survival of colorectal cancer patients in Italy have been estimated from cancer registry data. ${ }^{13}{ }^{14}$ Estimated incidence rates specific for the period 1980-1996 by sex, single year of age, and single calendar year were used to calculate the expected cumulative incidence probability for each subject in the study. The first two years after the date of initial colonoscopy/ polypectomy were not considered in the calculation of the probability of developing cancer. The expected number of cases in each subgroup of the study population was calculated by summing the expected incidence probabilities of all individuals belonging to the considered subgroup. For statistical testing and calculation of $95 \%$ confidence intervals (CI), observed and estimated numbers of cases were compared with those expected using the $\chi^{2}$ test with one degree of freedom. ${ }^{15}$

\section{Results}

Of the 1693 patients who were entered into the study, 1074 were men and 619 were women, with a mean age of 56 years (range 40-69) (table 1). Of these patients, 979 were followed up for more than 10 years whereas the mean follow up for the group was 10.5 years. Of interest is the fact that $1264(74 \%)$ subjects had a follow up TCE in the period 1992-1996 and among them 669 (40\%) in 1995-1996. For 237 subjects, follow up ended with a TCE.

A total of 165 patients were followed until death. Forty eight patients $(2.7 \%)$ were lost to follow up and were included in the persons/ years at risk until the last known alive date. All cases contributed individually to the persons/ years of follow up for a total of 14211 . At the time of enrollment, 721 patients $(43 \%)$ had adenomas of $0.5-0.9 \mathrm{~cm}$ and $972(57 \%)$ had an adenoma $\geqslant 1 \mathrm{~cm}$ (624 with adenomas $\geqslant 1.5$ $\mathrm{cm})$. Two hundred thirty three patients $(14 \%)$ had adenomas with high grade dysplasia.

Six colorectal cancer cases (four in males, two in females) at various stages were observed during the study (table 2): one at 29 months from the index examination, the others at five, seven, eight, and 10 years. Three patients with

Table 1 Characteristics of the study cohort and index lesions

\begin{tabular}{|c|c|}
\hline & No subjects (\%) \\
\hline Total No patients & 1693 \\
\hline Males & $1074(63.4)$ \\
\hline Females & $619(36.6)$ \\
\hline Mean age (y) & 56 \\
\hline \multicolumn{2}{|l|}{ No adenomas } \\
\hline One & $606(35.8)$ \\
\hline More than one & $1087(64.2)$ \\
\hline \multicolumn{2}{|l|}{ Size largest adenoma ${ }^{\star}$} \\
\hline $0.5-0.9 \mathrm{~cm}$ & $721(42.6)$ \\
\hline$\geqslant 1 \mathrm{~cm}$ & $972(57.4)$ \\
\hline \multicolumn{2}{|l|}{ Adenoma site ${ }^{\star}$} \\
\hline Colon right $\dagger$ & $148(8.7)$ \\
\hline Colon left $+\dagger$ & $1545(91.3)$ \\
\hline \multicolumn{2}{|l|}{ Worst histology ${ }^{\star \star}$} \\
\hline Tubular & $1132(66.8)$ \\
\hline Tubulo-villous & $460(27.2)$ \\
\hline Villous & $101(6)$ \\
\hline High grade dysplasia & $233(14)$ \\
\hline
\end{tabular}

$\star$ Size and location of adenomas refer to the larger lesion. ${ }^{\star \star}$ Refers to WHO criteria.

†Includes caecum, ascending, transverse, and splenic flexure. t十Includes descending, sigmoid, and rectum 
Table 2 Characteristics of the six patients with colorectal cancer detected at follow up

\begin{tabular}{|c|c|c|c|c|c|c|}
\hline & No 1 & No 2 & No 3 & No 4 & No 5 & No 6 \\
\hline Age at initial colonoscopy/ polypectomy (y) & 53 & 62 & 64 & 65 & 56 & 54 \\
\hline Sex & M & $M$ & $M$ & M & $\mathrm{F}$ & $\mathrm{F}$ \\
\hline Location of index adenoma & Sigmoid & Sigmoid & Descending & Sigmoid & Rectum & Sigmoid \\
\hline Histological finding at index examination & $\begin{array}{l}\text { Tubular } \\
\text { adenoma }\end{array}$ & $\begin{array}{l}\text { Tubulo-villous } \\
\text { adenoma }\end{array}$ & $\begin{array}{l}\text { Tubulo-villous } \\
\text { adenoma }\end{array}$ & $\begin{array}{l}\text { Tubulo-villous adenoma } \\
\text { pedunculated }\end{array}$ & $\begin{array}{l}\text { Tubulo-villous } \\
\text { adenoma }\end{array}$ & $\begin{array}{l}\text { Tubular } \\
\text { adenoma }\end{array}$ \\
\hline Size of index adenoma (mm) & 10 & 10 & 13 & 40 & 20 & 5 \\
\hline Lesions at index examination & $>1$ & $>1$ & $>1$ & 1 & $>1$ & 1 \\
\hline Grade of dysplasia of index adenoma & Not available & Moderate & Severe & Moderate & Severe & Severe \\
\hline Time from index examination $(y)$ & 7 & 10 & 8 & 5 & 5 & 2.5 \\
\hline No TCEs after index examination & 0 & 0 & 0 & 4 & 1 & 3 \\
\hline Location of cancer & Rectum & Transverse & Descending & Caecum & Rectum & Caecum \\
\hline Current status & Alive & Alive & Alive & Died from colon cancer & $\begin{array}{l}\text { Died from rectal } \\
\text { cancer }\end{array}$ & $\begin{array}{l}\text { Died from colon } \\
\text { cancer }\end{array}$ \\
\hline
\end{tabular}

^TCE, total colon examination.

Table 3 Results of the Italian multicentre study: observed versus expected incidence of colorectal cancer. Total number of study subjects 1693

\begin{tabular}{lllll}
\hline Sex & $\begin{array}{l}\text { Person/years of } \\
\text { follow up }\end{array}$ & $\begin{array}{l}\text { Observed } \\
\text { cancers }\end{array}$ & $\begin{array}{l}\text { Expected } \\
\text { cancers }\end{array}$ & Incidence ratio and $95 \%$ CI \\
\hline Males & 8985 & 4 & 12.9 & $0.31(0.20-0.69) ; \mathrm{p}<0.05$ \\
Females & 5226 & 2 & 4.9 & $0.41(0.22-4.00) ; \mathrm{NS}$ \\
Total (M and F) & 14211 & 6 & 17.7 & $0.34(0.23-0.63) ; \mathrm{p}<0.01$ \\
\hline
\end{tabular}

cancer were dead at the time of follow up, at 29 months (one case in the caecum) and at five years (two cases, one in the caecum and one in the rectum). Of the three colorectal cancer cases excluded as missed lesions because they occurred within two years of the index examination, one was diagnosed at 13 months (sigmoid), one at three months (sigmoid), and one at eight months (descending colon; deceased).

Cases expected in the reference general population were 17.7 versus six in our study. The overall incidence ratio was 0.34 (CI $0.23-$ 0.63 ; $\mathrm{p}<0.01$ ): 0.31 in males (CI $0.20-0.69$; $\mathrm{p}<0.05$ ) and 0.41 in females (CI 0.22-4.00; NS) (table 3). Incidence ratios were also calculated for the size of adenomas: 0.13 (CI 0.08 $0.48 ; \mathrm{p}<0.05)$ for patients with adenomas $5-9$ $\mathrm{mm}$ and 0.49 (CI $0.30-1.25$; NS) for patients with adenomas more than $1 \mathrm{~cm}$; subject age at enrollment: 0.43 (CI $0.23-5.00$; NS) for ages 40-54 and 0.30 (CI $0.20-0.67 ; \mathrm{p}<0.05$ ) for ages 55-69.

\section{Discussion}

A prospective clinical trial (NPS) reported a lower than expected incidence of colorectal cancer following removal of adenomatous polyps. The authors concluded that their results supported the view that colorectal adenomas progress to adenocarcinomas, and also that the current practice of searching for and removing adenomatous polyps prevents colorectal cancer. ${ }^{1}$ The report provided evidence in support of our belief in the concept of adenoma to carcinoma progression. The study also suggested that the current practice of removing adenomas is an effective prevention strategy. The Italian multicentre collaborative study was organised to test if this approach was effective in clinical practice.

The Italian study obtained data from a group of clinical gastroenterologists practising at several centres throughout the country, representing the usual busy clinical schedule of gastrointestinal endoscopy units. It was striking that

the reduction in the incidence of colorectal cancer in their clinical environment closely approximated the reduction in incidence observed in the prospective clinical trial conducted by the NPS. In fact, our results support the suggestion of the NPS that their approach can be effective in the control of colorectal cancer in clinical practice. Furthermore, our data agree closely with the US NPS data in which five asymptomatic early stage cancers were observed compared with 20.7 expected in a general population reference database (SEER), with an incidence reduction of $76 \%$ in 8401 person/years of follow up. The baseline characteristics of our Italian cohort were similar to those of the US NPS in terms of multiplicity and histology of adenomas, and male/female ratio, but only patients with adenomas $\geqslant 0.5 \mathrm{~cm}$ were included.

In our series, six colorectal cancer cases were found at follow up (table 2). Mortality from cancer was probably due to missed lesions during the index examination (case Nos 4, 5, and 6): in case No 5, several rectal polyps were removed during one endoscopic session subsequent to the index examination but the patient did not comply with the six month scheduled recall, dying five years later with Dukes' D cancer. The two other cases underwent several colonoscopies (four and three, respectively) and cancer was diagnosed five years later (case No 4) and 2.5 years later (case No 6). The other cases were observed in patients at high risk who did not undergo follow up colonoscopy surveillance.

Despite the occurrence of six cancers, a significant reduction (odds ratio 0.34 ) in the incidence of colorectal cancer was observed in our cohort with respect to the general population (table 3).

We compared the risk of colorectal cancer in this cohort with the risk expected in the general population of similar age and sex as our cohort. Comparison with a general population provides a conservative estimate of risk because, as shown in a study performed by Atkin et al at St Mark's, ${ }^{16}$ adenoma patients without polypectomy intervention have twice the risk for subsequent colon cancer as the general population. Atkin et al further identified a subgroup of patients with adenomas $>1.0 \mathrm{~cm}$, or with tubulovillous or villous adenomas who had a 3.6-fold increased risk of colon cancer. Our study was restricted to patients with at least one adenoma of $>0.5 \mathrm{~cm}$ but $57 \%$ had an adenoma 
of $>1.0 \mathrm{~cm}$, the high risk category in Atkin's paper. If we reduce the risk by $10 \%$ to account for exclusion of high familial risk patients, and increase the risk to the general population to 3.6 , as in Atkin's study, for the $57 \%$ of our patients with adenomas $>1.0 \mathrm{~cm}$, we estimate 32.7 colorectal cancers would have occurred in our cohort if no polypectomy intervention had occurred. The revised standardised incidence rate would be $6 / 32.7$ or 0.18 .

Reduction in the incidence of colorectal cancer following polypectomy has direct relevance to general population screening. Adenomatous polyp is the most common finding in patients with a positive faecal occult blood test (FOBT) or sigmoidoscopy.

Four prospective FOBT $^{17-20}$ trials and two sigmoidoscopy case control studies ${ }^{2}{ }^{3}$ demonstrated a reduction in mortality for colorectal cancer. The reduction in mortality observed in the FOBT trials was $15-33 \%$, the greatest reduction being seen in the Minnesota trial, in which a sensitive test was offered every year. The reduction in mortality was a result of identifying and treating earlier stage cancers by colonoscopy in patients with a positive FOBT. As noted in the UK trial, many adenomatous polyps were identified as a result of screening. ${ }^{19}$ We would expect a second, later effect on mortality as a result of a reduction in the incidence of colorectal cancer following removal of adenomas in these patients. This would make screening more cost effective. A reduction in incidence is being reported from the Minnesota trial as a result of polypectomy. ${ }^{21}$ Additional studies have been reported ${ }^{22}{ }^{23}$ or are in progress (prostate, lung, colon, and ovarian screening trial- $\mathrm{PLCO}^{24}$; National Screening Colonoscopy Trial; Once offered Sigmoidoscopy Screening Trial $^{25}$ ) addressing the question of colorectal cancer control through an incidence reduction effect on mortality rather than only finding early stage cancers through screening.

In conclusion, our data support the concept of the adenoma-carcinoma sequence as the major pathway of colon carcinogenesis. In addition, we have demonstrated that intervention in this pathway in clinical practice has the potential to reduce the incidence of colorectal cancer. The magnitude of this reduction was similar to that seen in the National Polyp Study. Our study demonstrates that it is possible to achieve this benefit in general clinical practice.

\section{Appendix}

CENTRES PARTICIPATING IN THE ITALIAN MULTICENTRE TRIAL

V Casale and V Stigliano, Endoscopy Service and Gastroenterology Unit, National Cancer Institute "Regina Elena", Rome, Italy; A Franzè and G Sabadini, Division of Gastroenterology, "Civil Hospital", Parma, Italy; S Morini and R Lorenzetti, Gastroenterology Service, "Nuovo Regina Margherita" Hospital, Rome, Italy; FP
Rossini and T Sprujevnik, Division of Gastroenterology, "San Giovanni Hospital", Torino, Italy; A Russo and A Magnano, Endoscopy Service, University, Catania, Italy; P Spinelli and E Barbieri, Endoscopy Service, National Cancer Institute, Milano, Italy; and F Manenti and AM Rebecchi, Division of Gastroenterology, University, Modena, Italy.

The authors thank Drs Sidney Winawer and Ann Zauber, Memorial Sloan-Kettering Cancer Center (New York, USA), for kindly reviewing the manuscript and providing constructive
criticism. Supported by a grant from the Italian Association for criticism. Supported by a g
Cancer Research (AIRC).

1 Winawer SJ, Zauber AG, Ho $\mathrm{MH}$, et al, and the National Polyp Study Workgroup. Prevention of colorectal cancer by colonoscopy polypectomy. N Engl f Med 1993;327:197781 .

2 Selby JV, Friedman GD, Quesenberry CP, et al. A case-control study of screening sigmoidoscopy and mortality from colorectal cancer. N Engl f Med 1992;326:6537.

3 Newcomb PA, Norfleet RG, Storer BE, et al. Screening sigmoidoscopy and colorectal cancer mortality. $\mathcal{F}$ Natl Cancer Inst 1992;84:1572-5.

4 Muller AD, Sonnenberg A. Prevention of colorectal cancer by flexible endoscopy and polypectomy. A case-control study of 32,702 veterans. Ann Intern Med 1995;18:494500 .

5 Morson BC, Sobin LH, eds. Histological typing of intestinal tumours. International histological classification of tumours. Geneva: World Health Organization, 1976:15.

6 De Angelis R, Valente F, Frova L, et al. Trends of colorectal cancer incidence and prevalence in Italian regions. Tumori 1999;84:1-8.

7 Verdecchia A, Capocaccia R, Egidi V, et al. A method for the estimation of chronic disease morbidity and trends from estimation of chronic disease morbidity
mortality data. Stat Med 1989;8:201-16.

8 De Angelis G, De Angelis R, Frova L, et al. MIAMOD: a computer package to estimate chronic disease morbidity using mortality and survival data. Comput Programs Biomed 1994;44:99-107.

9 Capocaccia R, De Angelis R, Frova L, et al. Estimation and projections of colorectal cancer trends in Italy. Int $\mathcal{F}$ Epidemiol 1997;26:924-32.

10 Capocaccia R, Verdecchia A, Micheli A, et al. Breast cancer incidence and prevalence estimated from mortality and survival. Cancer Causes Control 1990;1:23-9.

11 Capocaccia R, Micheli A, Berrino F, et al. Time trends of lung and larynx cancer in Italy. Int f Cancer 1994;57:1-8.

12 Capocaccia R, De Angelis R, Frova L, et al. Estimation and projections of stomach cancer trends in Italy. Cancer Causes Control 1995;6:339-46.

13 De Angelis R, Capocaccia R, Verdecchia A. Estimating relative survival of Italian cancer patients from sparse registries tive survival of Italian cancer

14 Verdecchia A and the ITACARE Working Group. Survival in adult Italian cancer patients. Tumori 1997;83:39-42.

15 Baylar JC, Ederer F. Significance factors for the ratio of a Poisson variable to its expectation. Biometrics 1964;60:63942.

16 Atkin WS, Morson BC, Cuzick J. Long-term risk of colorectal cancer after excision of rectosigmoid adenomas. $N$ Engl 7 Med 1992;326:658-62.

17 Mandel JS, Bond JH, Church TR, et al, for the Minnesota Colon Cancer Control Study: Reducing mortality from colorectal cancer by screening for fecal occult blood. $N$ Engl F Med 1993;328:1365-71.

18 Winawer SJ, Flehinger B, Schottenfeld D, et al. Screening for colorectal cancer with fecal occult blood testing and sigmoidoscopy. $\mathcal{F}$ Natl Cancer Inst 1993;85:1311-18.

19 Hardcastle JD, Chamberlain JO, Robinson MHE, et al. Randomised controlled trial of faecal occult blood screening for domised controlled trial of faecal occult bloo

20 Kronborg O, Fenger C, Olsen J, et al. Randomised study of screening for colorectal cancer with fecal occult blood test screening for colorectal cancer with fecal occult b
at Funen in Denmark. Lancet 1996;348:1467-71.

21 Mandel JS, Church TR, Bond JH, et al. The effect of fecal occult blood screening on the incidence of colorectal cancer. N Engl F Med 2000;343:1603-7.

22 Imperiale TF, Wagner DR, Lin CY, et al. Risk of advanced proximal neoplasms in asymptomatic adults according to the distal colorectal findings. N Engl f Med 2000;343:16974.

23 Lieberman DA, Weiss DG, Bond JH, et al. Use of colonoscopy to screen asymptomatic adults for colorectal cancer. N Engl f Med 2000;343:162-8.

24 Gohagan JK, Prorok PC, Kramer BS, et al. The prostate, lung, colorectal, and ovarian cancer screening trial of the National Cancer Institute. Cancer 1995;75:1869-73.

25 Atkin WS, Edwards R, Wardle J, et al. UK randomised trial of once-only flexible sigmoidoscopy screening: baseline results. Endoscopy 1999;31: E1. 